\title{
Shotgun Phage Display of Lactobacillus casei BL23 Against Collagen and Fibronectin
}

\author{
Muñoz-Provencio, Diego and Vicente Monedero* \\ Laboratorio de Bacterias Lácticas y Probióticos, Instituto de Agroquímica y Tecnología de Alimentos-CSIC, Av. Agustín Escardino \\ 7, 46980 Paterna, Valencia, Spain
}

Received: September 9, 2010 / Revised: November 16, 2010 / Accepted: November 17, 2010

\begin{abstract}
Lactobacilli are normal constituents of the intestinal microbiota, and some strains show the capacity to bind to extracellular matrix proteins and components of the mucosal layer, which represents an adaptation to persist in this niche. A shotgun phage-display library of Lactobacillus casei BL23 was constructed and screened for peptides able to bind to fibronectin and collagen. Clones showing binding to these proteins were isolated, which encoded overlapping fragments of a putative transcriptional regulator (LCABL_29260), a hypothetical protein exclusively found in the $L$. casei/rhamnosus group (LCABL_01820), and a putative phage-related endolysin (LCABL_13470). The construction of different glutathione S-transferase (GST) fusions confirmed the binding activity and demonstrated that the three identified proteins could interact with fibronectin, fibrinogen, and collagen. The results illustrate the utility of phage display for the isolation of putative adhesins in lactobacilli. However, it remains to be determined whether the primary function of these proteins actually is adhesion to mucosal surfaces.
\end{abstract}

Keywords: Lactobacillus, probiotic, phage display, extracellular matrix

Bacterial adhesion to the intestinal epithelium is an important characteristic to persist in the gastrointestinal tract. In the probiotic field, adhesion has been a classical criterion for strain selection, and in the past years, extensive research has been performed in the extracellular biology of probiotic lactobacilli with the aim of identifying surface adhesins $[6,15,22,28]$. However, information about the mechanisms and molecules implicated is still

* Corresponding author

Phone: +34 963900022; Fax: +34 963636301;

E-mail: btcmon@iata.csic.es limited for this group of microorganisms. Many lactobacilli bind to mucin, a component of the mucosal layer, and species of intestinal origin display specialized mucin-binding proteins on their surface $[5,29]$. Lactobacilli also showed ability to bind to extracellular matrix (ECM) proteins like fibronectin, collagen, laminin, or fibrinogen $[8,16,19,26]$, which normally are not exposed in the mucosal layer but can be of crucial importance in attachment and probiotic activity (displacement and competition to pathogens) under certain circumstances. The search for adhesins to ECM present in the outer surface of the cell-wall from lactobacilli always led to the isolation of moonlighting proteins implicated in other bacterial processes [22, 28]. As an example, glycolytic enzymes such as enolase [7] and glyceraldehyde-3-phosphate dehydrogenase [23] are displayed in the surface of some lactobacilli and possess binding ability to a variety of ECM proteins. Therefore, the in silico search of putative adhesion factors in lactobacilli becomes a difficult task.

In the shotgun phage-display technique, random DNA fragments of a given organism are fused to a viral capsid protein-encoding gene to construct a library of phages that express the peptides derived from the DNA sequences on their surfaces [14]. This allows the isolation of specific binding peptides after successive rounds of panning, and selection of the modified viral particles on a particular target. This technique has been successfully applied to isolate several adhesins from streptococcal and staphylococcal strains $[4,12,13]$ and, recently, allowed the isolation of a 29 amino acid peptide derived from an ABC transporter from the intestinal probiotic Bifidobacterium longum, which interacted with HT-29 epithelial cells [25]. The procedure has the advantage that no prior information on the genomic sequence of the microorganism under study is needed. Furthermore, the identification of interacting peptides within a protein sequence provides valuable information about domains involved in binding. 
Lactobacillus casei is a natural inhabitant of the digestive tract and many strains show probiotic effects, for which it is included in a variety of probiotic products. $L$. casei BL23 is a strain with health-promoting effects in animal models [9,21,31] whose genome has been recently sequenced [17]. In this strain, protein-dependent binding to fibronectin and collagen has been reported $[19,20]$. In the present work, we constructed and screened a shotgun phage-display library of $L$. casei BL23 against collagen and fibronectin and identified peptides derived from proteins of this microorganism that interacted with these ECM proteins.

\section{Materials ANd Methods}

\section{Strains and Growth Conditions}

L. casei BL23 [1, 17] was used for chromosomal DNA isolation and it was grown in MRS medium (Difco) at $37^{\circ} \mathrm{C}$ under static conditions. E. coli $\mathrm{DH} 5 \alpha$ was used for gene cloning, and $E$. coli BL21(DE3)[pLysS] was used for protein expression and purification. E. coli TG1 was used as a host for M13 phage propagation. E. coli strains were grown in LB or $2 \times \mathrm{TY}(16 \mathrm{~g}$ tryptone, $10 \mathrm{~g}$ yeast extract, and $5 \mathrm{~g} \mathrm{NaCl}$, per liter) medium at $37^{\circ} \mathrm{C}$ under agitation. Antibiotics used were ampicillin at $100 \mu \mathrm{g} / \mathrm{ml}$, chloramphenicol at $20 \mu \mathrm{g} / \mathrm{ml}$, and kanamycin at $25 \mu \mathrm{g} / \mathrm{ml}$.

\section{Construction and Screening of an L. casei BL23 Shotgun Phage- Display Library}

A shotgun phage-display library was constructed in the phagemid vector pG8SAET essentially as previously described [14]. L. casei BL23 chromosomal DNA was fragmented by sonication, and fragments ranging from 0.1 to $2 \mathrm{~kb}$ were purified from an agarose gel and made blunt with T4 DNA polymerase. Ten $\mu \mathrm{g}$ of purified fragments was ligated to $10 \mu \mathrm{g}$ of pG8SAET vector previously digested with SnaBI and dephosphorylated with calf intestinal phosphatase. The ligation mixture was electroporated into E. coli TG1 with a Genepulser apparatus (BioRad) following the procedure recommended by the manufacturer. Transformed cells were resuspended in $50 \mathrm{ml}$ of $\mathrm{LB}$ and incubated at $37^{\circ} \mathrm{C}$ for $1 \mathrm{~h}$. The number of transformants was estimated by plating several dilutions on LB agar plates supplemented with ampicillin. Subsequently, ampicillin was added to $100 \mu \mathrm{g} / \mathrm{ml}$ to the cell suspension, and after an overnight incubation at $37^{\circ} \mathrm{C}, 2 \mathrm{ml}$ of the culture was infected with helper phage VCSM13 (Stratagene) at a multiplicity of infection of 10 for $30 \mathrm{~min}$ at $37^{\circ} \mathrm{C}$. The cell suspension was mixed with $50 \mathrm{ml}$ of melted $2 \times \mathrm{TY}$ soft agar [agar $0.5 \%(\mathrm{w} / \mathrm{v})]$ and $5-\mathrm{ml}$ aliquots were poured on $2 \times$ TY plates containing $50 \mu \mathrm{g} / \mathrm{ml}$ ampicillin and $25 \mu \mathrm{g} / \mathrm{ml}$ kanamycin. After an overnight incubation, the soft agar was scrapped off each plate and resuspended in $5 \mathrm{ml}$ of $2 \times \mathrm{TY}$. The mixture from all the plates was pooled and agitated (100 rpm) for $4 \mathrm{~h}$ at room temperature. After centrifugation at $4,000 \times g$ for $20 \mathrm{~min}$, the supernatant was filtered through $0.45 \mu \mathrm{m}$ filters and the medium containing recombinant phages $\left(1.1 \times 10^{12} \mathrm{pfu} / \mathrm{ml}\right)$ was stored in $1-\mathrm{ml}$ aliquots at $-80^{\circ} \mathrm{C}$.

Polysorp immunotubes $(75 \times 12 \mathrm{~mm}$, Nunc) or four wells of a $96-$ well Maxisorp immunoplate (Nunc) were covered with $20 \mu \mathrm{g} / \mathrm{ml}$ fibronectin (human plasma, Sigma) in $50 \mathrm{mM}$ carbonate buffer ( $\mathrm{pH}$ 9.6), or $20 \mu \mathrm{g} / \mathrm{ml}$ collagen (type I, Roche) in $10 \mathrm{mM}$ phosphate buffer (pH 5.5), $136 \mathrm{mM} \mathrm{NaCl}$, respectively, at $4^{\circ} \mathrm{C}$ overnight. Tubes and plates were washed three times with PBST (PBS plus $0.05 \%$ Tween 20 ) and blocked with PBS plus $0.1 \%$ BSA for $1 \mathrm{~h}$ at room temperature. Phages from the phage-display library were added to PBST plus $0.1 \%$ BSA and incubated for $4 \mathrm{~h}$. Unbound phages were removed by washing 25 times with PBST. Bound phages were eluted by incubation with $1 \mathrm{ml}$ of $50 \mathrm{mM}$ citrate buffer $(\mathrm{pH} 4)$ for $10 \mathrm{~min}$. The eluted phages were neutralized with $0.5 \mathrm{ml}$ of $2 \mathrm{M}$ Tris- $\mathrm{HCl}(\mathrm{pH} 8)$ and a $0.75-\mathrm{ml}$ aliquot was used to infect $9.25 \mathrm{ml}$ of an exponentially growing TG1 culture. Several dilutions were plated on $2 \times \mathrm{TY}$ plates with $100 \mu \mathrm{g} / \mathrm{ml}$ ampicillin to estimate the number of eluted phages and the cells were concentrated by centrifugation and plated on ten $2 \times$ TY agar plates supplemented with $100 \mu \mathrm{g} / \mathrm{ml}$ ampicillin. The resulting colonies were scrapped off the plates and infected with VCSM13 helper phage, as described above, to produce phage particles carrying pVIII fusions. Phages were recovered from the soft agar and used for further rounds of selection in new fibronectin- and collagen-coated immunotubes and plate wells.

\section{ELISA of Individual Clones}

Phages were rescued from several individual clones from the third round of selection and tested for their ability to bind fibronectin, collagen, and fibrinogen (fraction I from pig plasma, Sigma). ELISA plates covered with the substrates at $20 \mu \mathrm{g} / \mathrm{ml}$ were incubated with culture supernatants containing M13 phages carrying pVIII fusions $\left(10^{7} \mathrm{pfu} / \mathrm{ml}\right)$ obtained from individual TG1 clones in PBS plus $2 \%$ BSA. Bound M13 clones were detected with a horseradish peroxidaseconjugated anti-M13 antibody according to the instructions of the Detection Module Recombinant Phage Antibody System (GE Healthcare). Plasmid from positive clones was isolated and the inserts sequenced with the oligonucleotide SAET3 (5'-TTATCAGCTTGCT TTCGAGG). Homology searches were performed with BLAST at the National Center for Biotechnology Information (http:// www.ncbi.nlm.nih.gov) and the sequences were aligned with DNAMAN (Lynnon Corporation).

\section{Protein Expression and Purification}

Recombinant proteins were expressed as glutathione S-transferase (GST) fusion proteins from plasmid pGEX2t (GE Healthcare). To this end, $L$. casei genes were amplified by PCR using Platinum $P f x$ DNA polymerase (Invitrogen) and chromosomal DNA from L. casei BL23. The locus LCABL_01820 was amplified with the oligonucleotides LCABL_01820For (5'-GGTGGATCCATGGAACA CTATGC) and LCABL_01820Rev (5'-CAAGAATTCTCAACTGG CAGTTTC). Restriction sites introduced for cloning are underlined. The PCR product was digested with BamHI and EcoRI and cloned into pGEX2t digested with the same enzymes to give a GSTLCABL_01820 fusion. Full-length LCABL_29260 (xpkR) was amplified with the oligonucleotides DeoRF (5'-GCGAGATCTATGA ATAGCATCGA) and DeoRR2 (5'-GGTGAATTCTTAGACGATCA CCTT) and a fragment encoding the first 88 amino acids of XpkR was amplified with the oligonucleotide pair DeoRF and. DeoRR1 (5'-GCCGAATTCTTAAAGTTTAACTGCATT). Both PCR products were digested with $B g l I I$ and $E c o$ RI and ligated to pGEX2t digested with BamHI and EcoRI, resulting in plasmids expressing GST-

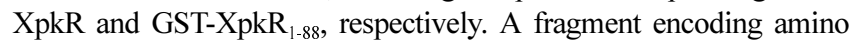
acids 29 to 80 from ps356 was amplified with oligonucleotides EndoFor (5'-GTCGGATCCGCCAAGGGTGATCAGGGC) and EndoRev (5'- 
TGCGAATTCGGCACTAGCAATTTGGCT). The PCR fragment was digested with BamHI and EcoRI and cloned into pGEX2t to produce a GST-ps356 $29-80$ fusion. The four constructed plasmids were verified by sequencing and transformed into $E$. coli BL21(DE3)[pLysS]. Purification of GST fusion proteins was carried out from $500-\mathrm{ml}$ cultures induced with $1 \mathrm{mM}$ isopropyl- $\beta$-Dthiogalactopyranoside. The proteins were purified in glutathione Sepharose $4 \mathrm{~B}$ columns ( $1 \mathrm{ml}$ bed volume) as recommended by the supplier (GE Healthcare).

\section{In Vitro Binding Assays}

Proteins were fixed to 96-well Polysorp immunoplates (Nunc) in $50 \mathrm{mM}$ carbonate buffer ( $\mathrm{pH}$ 9.6) (fibronectin, fibrinogen) or Maxisorp immunoplates (Nunc) in $10 \mathrm{mM}$ phosphate buffer (pH 5.5), $136 \mathrm{mM}$ $\mathrm{NaCl}$ (collagen) at $20 \mu \mathrm{g} / \mathrm{ml}(100 \mu \mathrm{l} /$ well $)$ overnight at $4^{\circ} \mathrm{C}$. Plates were washed three times with PBS and blocked with PBS containing $2 \% \mathrm{BSA}$ for $2 \mathrm{~h}$ at $37^{\circ} \mathrm{C}$. After washing three times with

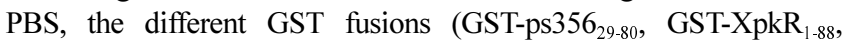
GST-XpkR, and GST-LCABL_01820) were added (10 $\mu \mathrm{g}$ in $100 \mu \mathrm{l}$ of PBS) and the plates were incubated overnight at $4^{\circ} \mathrm{C}$. The plates were washed four times with PBS, and GST activity was detected with $100 \mu \mathrm{l} /$ well of a solution containing $100 \mathrm{mM}$ phosphate buffer (pH 6.5), $1 \mathrm{mM}$ 1-chloro-2,4-dinitrobenzene, and $1 \mathrm{mM}$ reduced glutathione, by measuring changes in the absorbance at $340 \mathrm{~nm}$ over a $1 \mathrm{~h}$ period in an Multiskan Ascent plate reader (Thermo-Labsystems).

\section{RT-PCR}

Total RNA was isolated from $10 \mathrm{ml}$ of exponentially growing $L$. casei BL23 cells (OD550 nm of 0.9) using the Trizol reagent as recommended by the supplier (Invitrogen). The RNA was treated with RNase-free DNase I (Turbo DNA-free kit, Ambion), and $2 \mu \mathrm{g}$ was used to synthesize cDNA with the Superscript VILO cDNA synthesis kit as recommended by the manufacturer (Invitrogen). RNA (60 ng), cDNA (5 ng), and chromosomal DNA samples (100 ng) were used to amplify fragments from $x p k R$, LCABL_01820, and $p s 356$ with the oligonucleotide pairs DeoRF/DeoRR1, LCABL_01820For/ LCABL_01820Rev, and EndoFor/EndoRev, respectively, and the reaction products were separated in $1.5 \%$ agarose gels stained with ethidium bromide.

\section{RESUltS}

Identification of $L$. casei Peptides Interacting with Collagen and Fibronectin by Phage Display

An $L$. casei BL23 phage-display library was constructed in the vector pG8SAET [14]. The library consisted of $1.2 \times 10^{7}$ independent clones with random BL23 chromosomal fragments fused to the 5 ' end of the phage coat protein VIII gene. After three rounds of panning on collagen, overlapping clones spanning two different genes (LCABL 29260 and LCABL_01820; Fig. 1A) were obtained. Panning of the library on fibronectin resulted in the isolation of clones derived also from LCABL_29260 and of a new gene (LCABL_13470; Fig. 1A). The isolation of different overlapping clones confirmed that binding was due to a specific interaction with the displayed peptides. Fig. 1B
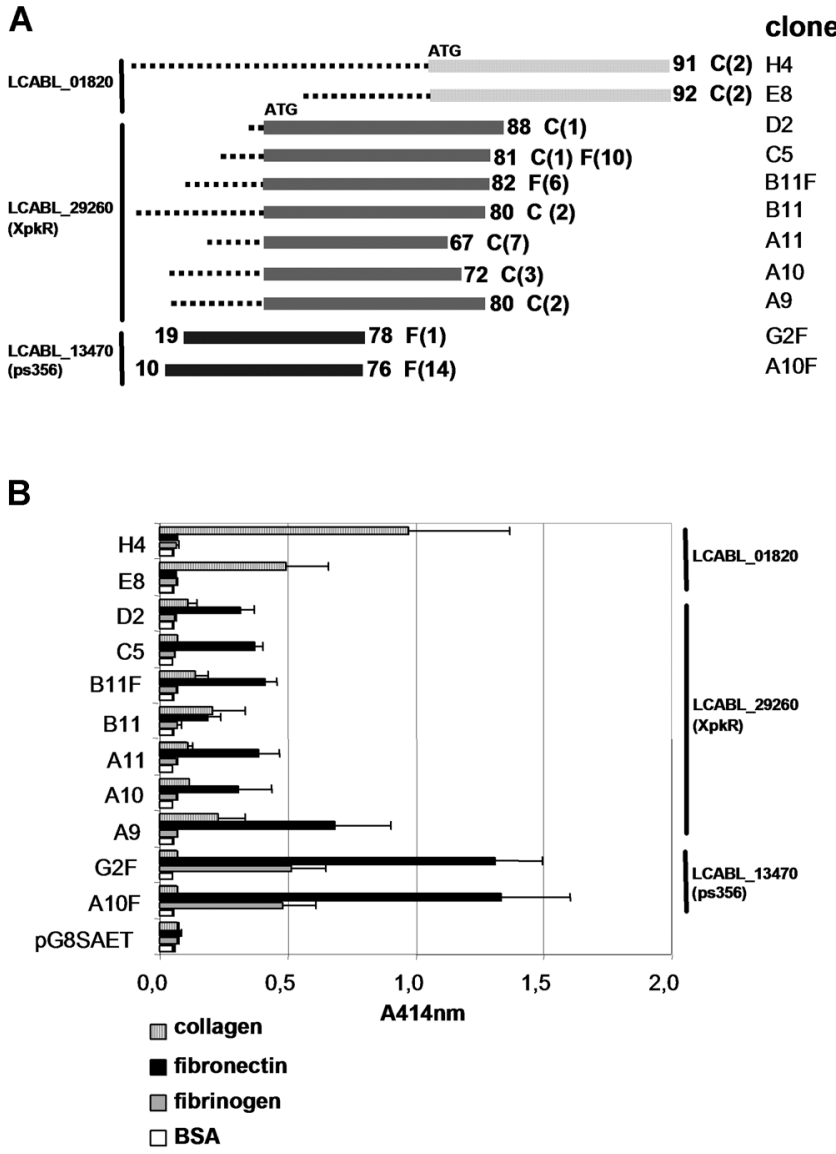

Fig. 1. Binding clones isolated by phage display.

A. Schematic representation of the DNA fragments present in each clone. Rectangles represent the length of each open reading frame and numbers indicate the encoded amino acid positions that were fused to the pVIII M13 protein. Dotted lines represent the $L$. casei BL23 5' noncoding sequences upstream the open reading frame in each clone. " $\mathrm{C}$ " means that the clones were isolated on collagen, whereas " $\mathrm{F}$ " means that the clones were isolated after panning on fibronectin. Numbers in parenthesis indicate the number of times that a particular fragment was isolated. The clone column shows the designations of the representative clones chosen for further analysis. B. ELISA analysis for binding to ECM proteins of representative M13 clones carrying different $\mathrm{pVIII}$ fusions. Results are derived from two independent experiments repeated in quadruplicate. Error bars are standard deviations.

shows an ELISA experiment with representative M13 clones carrying each $\mathrm{pVIII}$ fusion. In these experiments, BSA and fibrinogen were used as controls. No clone was able to bind BSA. On the contrary, in addition to fibronectin, the clones carrying LCABL_13470 fragments were also able to bind fibrinogen. Fragments from LCABL_29260 and LCABL_01820 always carried segments corresponding to the $5^{\prime}$ region of the genes and therefore LCABL_29260and LCABL_01820-pVIII fusion proteins were translated from the $L$. casei translational signals present in these segments. For LCABL_13470, the pVIII fusions were expressed from the signals carried by pG8SAET [14].

LCABL 29260 coded for a putative transcriptional regulator of the DeoR family. This family of regulators carry 
an N-terminal helix-turn-helix (H-T-H) DNA-binding domain and are usually controlling expression of genes related to sugar catabolism. This gene was located upstream of a gene encoding a putative phosphoketolase enzyme $(x p k)$, with homology to phosphoketolase-2 (xpk2) from Lactobacillus plantarum (79\% identity), an enzyme that displayed catalytic activity on xylulose-5-phosphate and fructose-6-phosphate [33]. The same genetic arrangement was observed in $L$. plantarum, Lactobacillus salivarius, and Lactobacillus sakei strains, for which the LCABL_29260 product was tentatively named $\mathrm{XpkR}$. The $x p k R$ clones encoded amino acids of the $\mathrm{N}$-terminal part of the protein, indicating that the binding ability resided at the putative $\mathrm{H}-\mathrm{T}-\mathrm{H}$ motif present in this region.

LCABL_01820 encoded a putative $12 \mathrm{kDa}, 101$ amino acid protein, with no evident secretion signal and for which homologs were only found in L. casei (ATCC334 and ATCC 25302; 100\% identity) and Lactobacillus rhamnosus strains (GG, HN001, Lc705, and LMS2-1; 91\% identity). Sequence analysis showed that the practical totality of the LCABL_01820 open reading frame ( 91 and 92 amino acids; Fig. $1 \overline{\mathrm{A}})$ was fused to the pVIII gene.

LCABL_13470 was similar (46\% identity) to the ps356 endolysin from Lactococcus lactis [32] and was annotated as a ps356-like protein in the L. casei BL23 genome. It consisted of a putative phage-related endolysin that contained LysM and SH3 domains, probably involved in cell-wall binding, in addition to a catalytic domain belonging to the glycosyl hydrolase family 25 (residues 36 to 214, endo- $N$-acetylmuramidase). A secretion signal peptide was predicted in the $L$. casei ps356 sequence with a likely cleavage site between positions 28 and 29 (SignalP 3.0 server; http://www.cbs.dtu.dk/services/SignalP/). Homologs to ps356 were also present in other lactobacilli belonging to the L. casei/rhamnosus group, with amino acid identities ranging from $63 \%$ to $92 \%$. L c casei $\mathrm{ps} 356$ was encoded within a prophage gene cluster (LCABL_12880 to LCABL_13480) with a typical structural organization containing putative lysogeny, replication, structural, and lysis modules resembling the structure of $L$. casei phages Flca1, A2, and Lrm1. Analysis of the cloned fragments revealed that the binding activity (amino acids 19 to 76 ) was located at the Nterminal catalytic domain (Fig. 1A).

\section{Ability of Purified XpkR, ps356, and LCABL_01820 to Bind Collagen and Fibronectin}

In order to test if the binding ability of the identified peptide, was independent of their presence at the M13 surface; several GST fusions were constructed and purified (Fig. 2). For LCABL_01820, the whole 101 amino acid protein was fused to GST, whereas for XpkR two variants were constructed. The first one carried 88 amino acids from the $\mathrm{N}$-terminus, whereas a second fusion carried the full-length protein. Finally, amino acids 29 to 80 from the

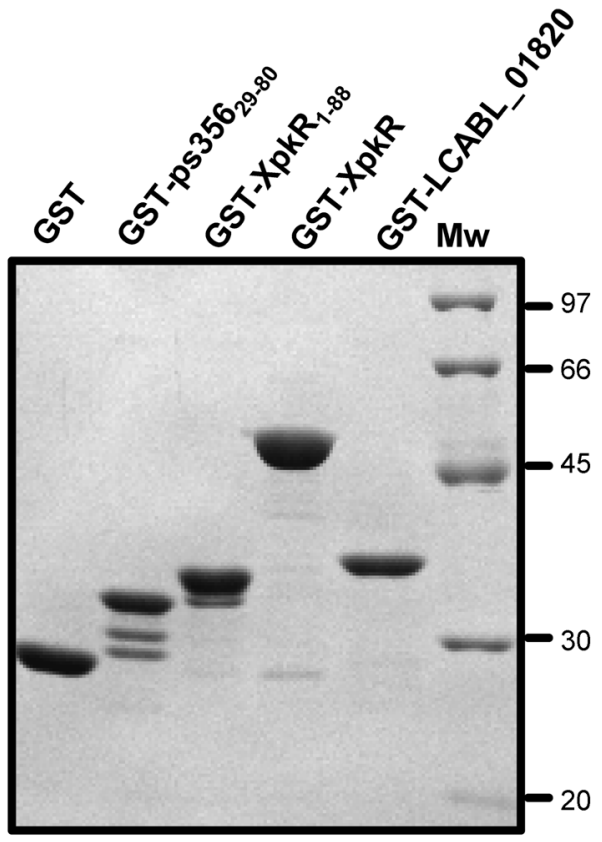

Fig. 2. Analysis of purified GST fusions carrying different amino acid segments of XpkR, ps356, and LCABL_01820 in a 12\% SDS-PAGE gel.

Numbers written as a suffix in XpkR and ps356 indicate the position numbers of the amino acids present in the fusions. Where no numbers are indicated, the full-length protein is fused. Numbers on the right are the molecular weights (Mw) of a protein marker, in $\mathrm{kDa}$.

ps356 N-terminus (excluding the signal peptide) were fused to GST.

The results presented in Fig. 3 demonstrate that the purified proteins retained their ability to bind to the assayed ECM proteins. Surprisingly, the three identified proteins were able to bind the three substrates to some extent. Similar to ELISA results with M13 phages, the product of LCABL_01820 had the maximum binding capacity to collagen, but it also showed the maximum level of binding to fibrinogen, even if no fibrinogen binding was detected when the peptide was located at the M13 surface (Fig. 1B). For XpkR, fusion of the whole protein to GST resulted in a loss of the binding capacity to collagen, suggesting that the N-terminal fusion of GST might be hampering the interaction of the N-terminus of XpkR with this protein. The activity determined with the GST control was low and at the level of the background obtained in wells where no protein was added, indicating that GST alone had no binding capacity.

Expression of $x p k R, p s 356$, and LCABL_01820 in $L$. casei BL23.

In order to determine whether the $x p k R, p s 356$, and LCABL_01820 genes were expressed in L. casei BL23 under our laboratory conditions, we examined their transcription by RT-PCR analysis. These experiments evidenced the 


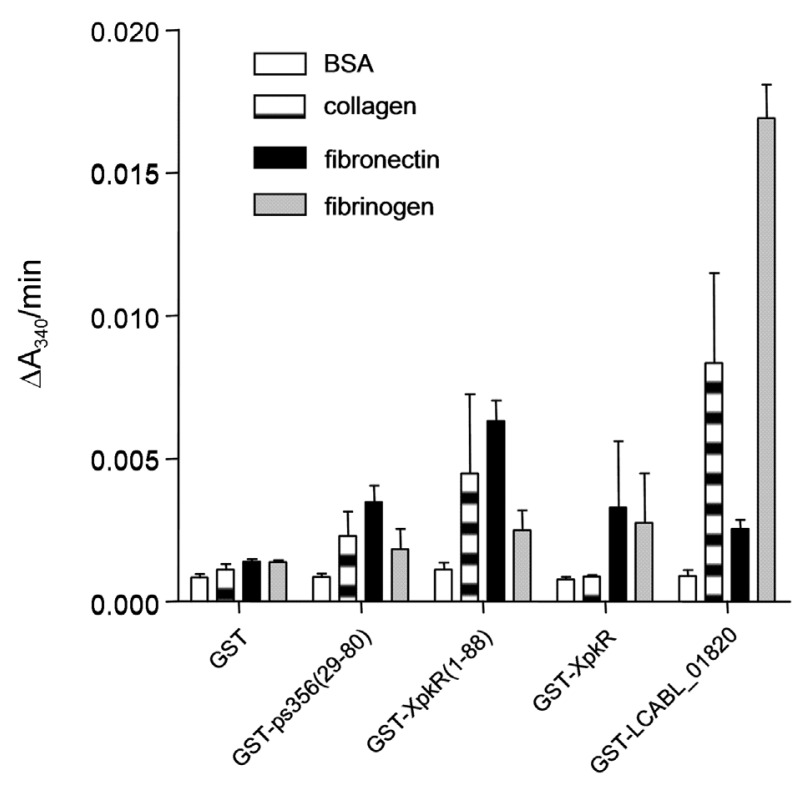

Fig. 3. Binding of GST fusions to different ECM proteins. After incubation of the different GST fusions in immunoplates coated with ECM proteins, unbound GST fusions were washed and bound proteins were detected by measuring GST activity spectrophotometrically with a coupled reaction at $340 \mathrm{~nm}$. Data are expressed as increments of the A340 nm per minute. Results are from two independent experiments repeated in quadruplicate. Error bars represent standard deviations.

presence of RNA transcripts for the three open reading frames (Fig. 4).

\section{Discussion}

Exoproteome analysis of lactobacilli shows that, analogous to other bacteria, these microorganisms present at their surfaces a variety of proteins with non-evident secretion signals involved in processes such as central metabolism, protein folding, stress response, and transcription and translation $[3,23]$. In some cases, these surface proteins are involved in the interaction with the host mucosa and behaved as sticky factors able to interact with the mucosal layer [23] or to activate defined host pathways [2].

In this work, the use of the phage-display technique led to the isolation of three proteins from $L$. casei BL23 with in vitro binding activity to ECM proteins. With the exception

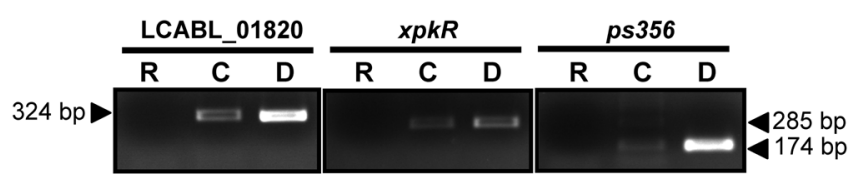

Fig. 4. RT-PCR analysis of the expression of LCABL_01820, $x p k R$, and $p s 356$ in L. casei $\mathrm{BL} 23$.

PCR was performed with RNA samples (lanes R), cDNA samples (lanes C), and chromosomal DNA (lanes D) as template. of the ps356 endolysin, the identified proteins lacked recognized secretion signals. The isolation of a protein with putative cell-wall hydrolytic activity is not surprising as many endolysins from bacterial pathogens have been reported to bind to the ECM and act as attachment factors involved in virulence $[11,27]$. The ps 356 gene was located within a prophage cluster, and detection of its transcription by RT-PCR evidenced that it was not a silent gene. This is not an anomalous situation, as mobilization of other prophages in a portion of the BL23 bacterial population has been detected by massive sequencing [17].

The second identified protein, $\mathrm{XpkR}$, is probably the transcriptional regulator of a gene (xpk) encoding an enzyme of the pentose metabolism [33]. Surface location of other transcriptional regulators has been described when analyzing the surface proteome of some microorganisms $[10,24]$, but the functionality of this location is unknown. The binding domain of XpkR resided at the $\mathrm{N}$-terminal DNA-binding region, and the presence of the C-terminal part of XpkR in the GST-XpkR fusion was hindering this domain to interact with collagen, but not with fibronectin or fibrinogen. This suggests that the spatial requirements for binding each substrate are different.

The third protein, the product of LCABL_01820, is a hypothetical protein with unknown function exclusively found in the L. casei/rhamnosus group. It showed a strong binding activity, but its specificity was dependent on the type of fusion employed in the assays. In analogy to the results with $\mathrm{XpkR}$, fusion of the product of LCABL_01820 to M13 pVIII prevented the binding of this protein to fibronectin and fibrinogen, whereas a GSTLCABL_01820 fusion interacted with the three assayed substrates. In this sense, the ps356 and LCABL_01820 clones were only isolated after panning on fibronectin and collagen, respectively, whereas the three identified proteins were able to attach to fibronectin, collagen, and fibrinogen. Lack of a strict binding specificity is a characteristic of others attachment factors in lactobacilli. As an example, the surface layer protein (SlpA) from Lactobacillus brevis ATCC 8287 was shown to interact with laminin, collagen, fibronectin, and fibrinogen [8], and a solute-binding protein from an $\mathrm{ABC}$ transporter in Lactobacillus reuteri $(\mathrm{CnBP})$ and Lactobacillus mucosae (Lam29) binds collagen, mucus, Caco-2 cells, and blood antigens $[18,30]$. This points to the idea that lactobacilli decorate their surface with nonspecific interacting proteins able to bind a broad spectrum of targets. However, it is not known at this stage whether the identified proteins participate in L. casei BL23 binding to ECM proteins.

The protein FbpA of $L$. casei BL23 has been recently described as possessing fibronectin-binding activity [20]. This protein was not identified during our phage-display screening. This could arise from one of the disadvantages of this technique: the interacting motifs are fused to a M13 
coat protein, which may affect phage viability and restricts the size of the displayed peptides [14]. Similarly, no fragments from enolase or glyceraldehyde-3-phosphate dehydrogenase enzymes were isolated, even though these proteins from $L$. casei BL23 show binding activity to collagen and fibronectin (our unpublished observations). This limits the use of phage display for the isolation of proteins with defined, not very large interacting domains that show strong binding.

In conclusion, we have constructed a highly represented L. casei BL23 phage-display library that can be useful to study interactions of this microorganism to host factors. Among the three identified proteins, we have characterized the product of a previous hypothetical gene (LCABL_01820) as a protein with binding capacity to ECM proteins. The length of the interacting domain (about 91 amino acids) and its binding characteristics open the possibility for its biotechnological application in lactobacilli for enhancement of ECM binding. Further genetic/biochemical analyses are required to assess the role of the identified proteins in $L$. casei interaction with the host.

\section{Acknowledgments}

We are grateful to Dr. Lars Frykberg for the generous gift of plasmid pG8SAET. This work was supported by projects AGL2004-00176/ALI and Consolider Fun-c-Food CSD2007-00063 from the Spanish Ministry of Science and Innovation. Diego Muñoz-Provencio was the recipient of a research fellowship from the Instituto Danone. We thank Dr. Manuel Zúñiga for critical reading.

\section{REFERENCES}

1. Acedo-Felix, E. and G. Perez-Martinez. 2003. Significant differences between Lactobacillus casei subsp. casei ATCC $393 \mathrm{~T}$ and a commonly used plasmid-cured derivative revealed by a polyphasic study. Int. J. Syst. Evol. Microbiol. 53: 67-75.

2. Antikainen, J., V. Kuparinen, K. Lahteenmaki, and T. K. Korhonen. 2007. Enolases from Gram-positive bacterial pathogens and commensal lactobacilli share functional similarity in virulence-associated traits. FEMS Immunol. Med. Microbiol. 51: 526-534.

3. Beck, H. C., S. M. Madsen, J. Glenting, J. Petersen, H. Israelsen, M. R. Norrelykke, M. Antonsson, and A. M. Hansen. 2009. Proteomic analysis of cell surface-associated proteins from probiotic Lactobacillus plantarum. FEMS Microbiol. Lett. 297: 61-66.

4. Bjerketorp, J., M. Nilsson, A. Ljungh, J. I. Flock, K. Jacobsson, and L. Frykberg. 2002. A novel von Willebrand factor binding protein expressed by Staphylococcus aureus. Microbiology 148: 2037-2044.

5. Boekhorst, J., Q. Helmer, M. Kleerebezem, and R. J. Siezen. 2006. Comparative analysis of proteins with a mucus-binding domain found exclusively in lactic acid bacteria. Microbiology 152: $273-280$.

6. Boekhorst, J., M. Wels, M. Kleerebezem, and R. J. Siezen. 2006. The predicted secretome of Lactobacillus plantarum WCFS1 sheds light on interactions with its environment. Microbiology 152: 3175-3183.

7. Castaldo, C., V. Vastano, R. A. Siciliano, M. Candela, M. Vici, L. Muscariello, R. Marasco, and M. Sacco. 2009. Surface displaced alfa-enolase of Lactobacillus plantarum is a fibronectin binding protein. Microb. Cell Fact. 8: 14.

8. de Leeuw, E., X. Li, and W. Lu. 2006. Binding characteristics of the Lactobacillus brevis ATCC 8287 surface layer to extracellular matrix proteins. FEMS Microbiol. Lett. 260: 210215 .

9. Foligne, B., S. Nutten, C. Grangette, V. Dennin, D. Goudercourt, S. Poiret, J. Dewulf, D. Brassart, A. Mercenier, and B. Pot. 2007. Correlation between in vitro and in vivo immunomodulatory properties of lactic acid bacteria. World J. Gastroenterol. 13: 236-243.

10. Hansmeier, N., T. C. Chao, J. Kalinowski, A. Puhler, and A. Tauch. 2006. Mapping and comprehensive analysis of the extracellular and cell surface proteome of the human pathogen Corynebacterium diphtheriae. Proteomics 6: 2465-2476.

11. Heilmann, C., J. Hartleib, M. S. Hussain, and G. Peters. 2005. The multifunctional Staphylococcus aureus autolysin aaa mediates adherence to immobilized fibrinogen and fibronectin. Infect. Immun. 73: 4793-4802.

12. Heilmann, C., S. Niemann, B. Sinha, M. Herrmann, B. E. Kehrel, and G. Peters. 2004. Staphylococcus aureus fibronectinbinding protein (FnBP)-mediated adherence to platelets, and aggregation of platelets induced by FnBPA but not by FnBPB. J. Infect. Dis. 190: 321-329.

13. Jacobsson, K. 2003. A novel family of fibrinogen-binding proteins in Streptococcus agalactiae. Vet. Microbiol. 96: 103-113.

14. Jacobsson, K., A. Rosander, J. Bjerketorp, and L. Frykberg. 2003. Shotgun phage display - selection for bacterial receptins or other exported proteins. Biol. Proced. Online 5: 123-135.

15. Kleerebezem, M., P. Hols, E. Bernard, T. Rolain, M. Zhou, R. J. Siezen, and P. A. Bron. 2010. The extracellular biology of the lactobacilli. FEMS Microbiol. Rev. 34: 199-230.

16. Lorca, G., M. I. Torino, G. Font de Valdez, and A. A. Ljungh. 2002. Lactobacilli express cell surface proteins which mediate binding of immobilized collagen and fibronectin. FEMS Microbiol. Lett. 206: 31-37.

17. Maze, A., G. Boel, M. Zuniga, A. Bourand, V. Loux, M. J. Yebra, et al. 2010. Complete genome sequence of the probiotic Lactobacillus casei strain BL23. J. Bacteriol. 192: 2647-2648.

18. Miyoshi, Y., S. Okada, T. Uchimura, and E. Satoh. 2006. A mucus adhesion promoting protein, MapA, mediates the adhesion of Lactobacillus reuteri to Caco-2 human intestinal epithelial cells. Biosci. Biotechnol. Biochem. 70: 1622-1628.

19. Munoz-Provencio, D., M. Llopis, M. Antolin, I. de Torres, F. Guarner, G. Perez-Martinez, and V. Monedero. 2009. Adhesion properties of Lactobacillus casei strains to resected intestinal fragments and components of the extracellular matrix. Arch. Microbiol. 191: 153-161.

20. Munoz-Provencio, D., G. Perez-Martinez, and V. Monedero. 2010. Characterization of a fibronectin-binding protein from Lactobacillus casei BL23. J. Appl. Microbiol. 108: 1050-1059. 
21. Rochat, T., L. Bermudez-Humaran, J. J. Gratadoux, C. Fourage, C. Hoebler, G. Corthier, and P. Langella. 2007. Anti-inflammatory effects of Lactobacillus casei B123 producing or not a manganesedependant catalase on DSS-induced colitis in mice. Microb. Cell Fact. 6: 22.

22. Sanchez, B., P. Bressollier, and M. C. Urdaci. 2008. Exported proteins in probiotic bacteria: Adhesion to intestinal surfaces, host immunomodulation and molecular cross-talking with the host. FEMS Immunol. Med. Microbiol. 54: 1-17.

23. Sanchez, B., J. M. Schmitter, and M. C. Urdaci. 2009. Identification of novel proteins secreted by Lactobacillus plantarum that bind to mucin and fibronectin. J. Mol. Microbiol. Biotechnol. 17: 158-162.

24. Schaumburg, J., O. Diekmann, P. Hagendorff, S. Bergmann, M. Rohde, S. Hammerschmidt, L. Jansch, J. Wehland, and U. Karst. 2004. The cell wall subproteome of Listeria monocytogenes. Proteomics 4: 2991-3006.

25. Shkoporov, A. N., E. V. Khokhlova, L. I. Kafarskaia, K. A. Pavlov, V. V. Smeianov, J. L. Steele, and B. A. Efimov. 2008. Search for protein adhesin gene in Bifidobacterium longum genome using surface phage display technology. Bull. Exp. Biol. Med. 146: 782-785.

26. Styriak, I., R. Nemcova, Y. H. Chang, and A. Ljungh. 2003. Binding of extracellular matrix molecules by probiotic bacteria. Lett. Appl. Microbiol. 37: 329-333.

27. Teng, F., M. Kawalec, G. M. Weinstock, W. Hryniewicz, and B. E. Murray. 2003. An Enterococcus faecium secreted antigen, SagA, exhibits broad-spectrum binding to extracellular matrix proteins and appears essential for $E$. faecium growth. Infect. Immun. 71: 5033-5041.

28. Velez, M. P., S. C. De Keersmaecker, and J. Vanderleyden. 2007. Adherence factors of Lactobacillus in the human gastrointestinal tract. FEMS Microbiol. Lett. 276: 140-148.

29. von Ossowski, I., J. Reunanen, R. Satokari, S. Vesterlund, M. Kankainen, H. Huhtinen, et al. 2010. Mucosal adhesion properties of the probiotic Lactobacillus rhamnosus GG spaCBA and spaFED pilin subunits. Appl. Environ. Microbiol. 76: 2049-2057.

30. Watanabe, M., H. Kinoshita, M. Nitta, R. Yukishita, Y. Kawai, K. Kimura, et al. 2010. Identification of a new adhesin-like protein from Lactobacillus mucosae ME-340 with specific affinity to the human blood group A and B antigens. J. Appl. Microbiol. 109: 927-935.

31. Watterlot, L., T. Rochat, H. Sokol, C. Cherbuy, I. Bouloufa, F. Lefevre, et al. 2010. Intragastric administration of a superoxide dismutase-producing recombinant Lactobacillus casei BL23 strain attenuates DSS colitis in mice. Int. J. Food. Microbiol. 144: 35-41.

32. Wegmann, U., M. O'Connell-Motherway, A. Zomer, G. Buist, C. Shearman, C. Canchaya, et al. 2007. Complete genome sequence of the prototype lactic acid bacterium Lactococcus lactis subsp. cremoris MG1363. J. Bacteriol. 189: 3256-3270.

33. Yevenes, A. and P. A. Frey. 2008. Cloning, expression, purification, cofactor requirements, and steady state kinetics of phosphoketolase-2 from Lactobacillus plantarum. Bioorg. Chem. 36: $121-127$. 